\title{
Emerging Roles for NLRC5 in Immune Diseases
}

\section{OPEN ACCESS}

Edited by:

Rajbir Bhatti,

Guru Nanak Dev University, India

Reviewed by:

Ji Wang,

Sun Yat-sen University, China

Francesco Maione,

University of Naples Federico II,

Italy

*Correspondence:

Qing-rong Xia

gingrong-xia@ahmucentre.com

Jun Li

lijunahmu@163.com

tThese authors have contributed equally to this work

Specialty section:

This article was submitted to Inflammation Pharmacology, a section of the journal

Frontiers in Pharmacology

Received: 13 August 2019

Accepted: 25 October 2019

Published: 19 November 2019

Citation:

Wang J-q, Liu Y-r, Xia Q, Chen R-n,

Liang J, Xia Q-r and Li J (2019)

Emerging Roles for NLRC5 in

Immune Diseases.

Front. Pharmacol. 10:1352.

doi: 10.3389/fphar.2019.01352

\author{
Jie-quan Wang ${ }^{1,2,3,4 t}$, Ya-ru Liu ${ }^{5 t}$, Quan Xia5 ${ }^{5}$ Ruo-nan Chen ${ }^{4,5}$, Jun Liang ${ }^{1,2,3}$, \\ Qing-rong Xia ${ }^{1,2,3 *}$, Jun $\mathrm{Li}^{4 *}$
}

${ }^{1}$ Department of Pharmacy, Hefei Fourth People's Hospital, Hefei, China, ${ }^{2}$ Department of Pharmacy, Anhui Mental Health Center, Hefei, China, ${ }^{3}$ Department of Pharmacy, Affiliated Psychological Hospital of Anhui Medical University, Hefei, China, ${ }^{4}$ School of Pharmacy, Anhui Medical University, Ministry of Education, Hefei, China, ${ }^{5}$ Department of Pharmacy, The First Affiliated Hospital of Anhui Medical University, Hefei, China

Innate immunity activates the corresponding immune response relying on multiple pattern recognition receptors (PRRs) that includes pattern recognition receptors (PRRs), like NOD-like receptors (NLRs), RIG-I-like receptors (RLRs), and C-type lectin receptors (CLRs), which could accurately recognize invasive pathogens. In particular, NLRs belong to a large protein family of pattern recognition receptors in the cytoplasm, where they are highly correlated with activation of inflammatory response system followed by rapid clearance of invasive pathogens. Among the NLRs family, NLRC5, also known as NOD4 or NOD27, accounts for a large proportion and involves in immune responses far and wide. Notably, in the above response case of inflammation, the expression of NLRC5 remarkably increased in immune cells and immune-related tissues. However, the evidence for higher expression of NLRC5 in immune disease still remains controversial. It is noted that the growing evidence further accounts for the participation of NLRC5 in the innate immune response and inflammatory diseases. Moreover, NLRC5 has also been confirmed to exert a critical role in the control of regulatory diverse signaling pathways. Together with its broad participation in the occurrence and development of immune diseases, NLRC5 can be consequently treated as a potential therapeutic target. Nevertheless, the paucity of absolute understanding of intrinsic characteristics and underlying mechanisms of NLRC5 still make it hard to develop targeting drugs. Therefore, current summary about NLRC5 information is indispensable. Herein, current knowledge of NLRC5 is summarized, and research advances in terms of NLRC5 in characteristics, biological function, and regulatory mechanisms are reviewed.

Keywords: NLRC5, NOD-like receptors, immune diseases, biological functions, signaling pathways

\section{INTRODUCTION}

The innate immune system has always been a striker against pathogenic microorganisms such as bacteria, fungi, and viruses (Akira et al., 2006; Medzhitov, 2007). Innate immunity is also responsible for most inflammatory responses, and the stress of innate immunity also reflects the status of the pathogen-specific adaptive immunity (Janeway and Medzhitov, 2002; Beutler, 2004). Innate immunity activates the corresponding immune response, requiring multiple pattern recognition receptors (PRRs) that recognize the molecular structures of specific pathogens in different cellular components, such as the cytoplasmic membrane, endosomes, and cytoplasm (Janeway, 1989; 
Kumar et al., 2009). To date, it was demonstrated that multiple families of PRRs includes NOD-like receptors (NLRs), Toll-like receptors (TLRs), RIG-I-like receptors (RLRs) and C-type lectin receptors (CLRs) (Inohara et al., 2005; Meylan and Tschopp, 2006; Kanneganti et al., 2007; Lamkanfi and Dixit, 2009). Despite relatively large differences in their structures, expressions, and localizations, all of them can specifically recognize invading pathogens and further initiate the innate and adaptive immune response when organism suffers from intrusion of non-self's pathogens (Table 1) (Yoneyama and Fujita, 2009; Dixit and Kagan, 2013; Dambuza and Brown, 2015; Kouli et al., 2019). Among PRRs family, NLRs account for a large proportion in the cytoplasm, where involves in inflammatory diseases and promotes the rapid clearance of invasive pathogens ( $\mathrm{Xu}$ et al., 2015; Yang et al., 2016). It was reported that NLRC5 is one of the largest members of the NLRs family, which could modulate inflammatory responses and many other human diseases (Rodriguez et al., 2016; Qiu et al., 2017). It has been demonstrated that the expression of NLRC5 increased significantly in immune cells and immune-related tissues of inflammatory response case, and NLRC5 also showed contradictory roles in the modulation of immune response (Benko et al., 2010; Cui et al., 2010; Yao and Qian, 2013). Accordingly, NLRC5 is emerging as a novel therapeutic target, which is rapidly attracting more extensive attention in many other inflammatory diseases. Meanwhile, accumulating evidence suggested that NLRC5 plays vital regulatory role in the occurrence and development of immune diseases. Therefore, a thorough understanding of the biological functions and potential molecular mechanisms of NLRC5 may give us inspirations on the development of therapeutic drugs targeting NLRC5. Following recent advances, this paper aims to provide a comprehensive update on the diverse pharmacological roles of NLRC5 in the process of immune diseases, especially on liver diseases, renal diseases, rheumatoid arthritis, heart diseases, lung diseases, and spleen diseases.

\section{STRUCTURE, EXPRESSION, AND LOCALIZATION}

At present, there are 23 NLR genes in the human genome and at least 34 NLR genes in the mouse genome that are expressed widely in various cells and tissues (Harton et al., 2002; Inohara and Nunez, 2003). It is commonly known that the NLRs protein is featured with a nucleotide-binding site (NBS) of tripartite domain structure, which contains leucine-rich repeat genes (LRR). (Ting et al., 2008; Wilmanski et al., 2008). The C-terminal of NLRs is generally considered to be the recognition and binding domain of microbial sources ligands, which corresponds to a danger signal sensor. While the $\mathrm{N}$-terminal is a variable effect domain

Abbreviations: PRRsm, pattern recognition receptors; NLRs, NOD-like receptors; NLRC5, NLR family, CARD domain containing 5; TLRs, Toll-like receptors; RLRs, RIG-I-like receptors; CLRs, C-type lectin receptors; CARD, caspase recruitment domain; PYD, pyrin domain domain; BIR, baculovirus inhibitor repeat; NBD, nucleotide-binding oligomerization domain; MHC-I, major histocompatibility complex-I; HSC, hepatic stellate cells; ALD, alcoholic liver disease; IRI, ischemia reperfusion injury; ECM, extracellular matrix. that composed of caspase recruitment domain (CARD), a pyrin domain (PYD) and baculovirus inhibitor repeat domain (BIRD) (Bertin and DiStefano, 2000; Koonin and Aravind, 2000; Inohara and Nuñez, 2001; Martinon et al., 2001; Pawłowski et al., 2001; Staub et al., 2001). Similarly, they all have a central nucleotidebinding oligomerization domain (NOD), which could eventually lead to the oligomerization and activation of NLRs (Birnbaum et al., 1994; Fairbrother et al., 2001; Weber and Vincenz, 2001; Tschopp et al., 2003). Synchronously, NLRs also could be subdivided into several subfamilies depending on the difference of N-terminal effector domains, such as CARDs. CARD domain containing 5 (NLRC5) is one of the largest members of the CARDs family (Ting et al., 2008). Petrus et al. initially revealed the precise structural feature of the caspase recruitment domain of mouse NLRC5 and subsequently indicated that atypical CARD of mouse NLRC5 and the tandem CARD mouse RIG-I might interact through the hydrophobic surface formed by a-helices 1 and 6 and the $a 5$ - $\alpha 6$ loop (Gutte et al., 2014). These promising discoveries may contribute to designing and synthesizing novel small molecular compounds targeting NLRC5. For another, microbial components, NLRC5 expression, and the pro-inflammatory cytokines have been respectively detected in a variety of immune tissues and cells of inflammatory disease. Simultaneously, these studies also indicated that NLRC5 may play a crucial role in specifically recognizing pathogenic microorganisms of nonself and negatively regulating the expression of inflammatory cytokines (Benko et al., 2010; Cui et al., 2010; Kuenzel et al., 2010; Meissner et al., 2010). Besides, the gene of NLRC5 has been found in many species, such as humans, mice, horses, and pig (Meissner et al., 2012). On one hand, some exploratory research has revealed that NLRC5 mRNA expression decreased slightly in immune diseases. (Kuenzel et al., 2010). On the other hand, several studies have also shown that the mRNA expression of NLRC5 increased dramatically in human and mouse immune tissues of immune disease, including bone marrow, lymph nodes, thymus, and spleen (Neerincx et al., 2010; Davis et al., 2011). To sum up, NLRC5 predominantly exists in bone marrow, human THP-1 cells, B cells, human cervical cancer cell line, and primary cells of myeloid and lymphoid origin. Based on advanced research, we made an in-depth discussion about the expression of NLRC5 in immune tissues and cells of different species, which influenced by inflammation (Table 2). The gene of NLRC5 locates in human chromosome 16q13, which straddles about $94 \mathrm{kbp}$ and encodes a protein with molecular mass of $204 \mathrm{kDa}$. Although it is not absolute, the NLRs are mainly localized to the cytoplasm and then play a vital role in recognition of pathogen and host defense (Franchi et al., 2009). The previous studies have also suggested that NLRC5 is predominantly localized in the cytoplasm rather than the nucleus or mitochondria in 293T cells transfected with NLRC5-GFP fusion DNA (Cui et al., 2010). Furthermore, some studies have indicated that NLRC5 has similar properties of transcriptional regulation with CIITA, which also may be a nuclear localization protein molecule that could shuttle between the nucleus and the cytoplasm. In fact, it was observed that NLRC5 was located in the nucleus in normal physiological condition. Also, NLRC5 with high expression tends to be localized in the nucleus when Leptomysin B, an inhibitor 
TABLE 1 | Implications (structure, expression, and location) of PRRs family.

\begin{tabular}{|c|c|c|c|c|c|c|}
\hline PRRs & $\begin{array}{l}\text { Representative } \\
\text { protein }\end{array}$ & Structure & Expression & Location & Involvements & References \\
\hline NLRs & NLRC5 & $\begin{array}{l}\text { Nucleotide binding } \\
\text { domains, } \\
\text { Leucine-rich repeat } \\
\text { genes, } \\
\text { Triple domain }\end{array}$ & $\begin{array}{l}\text { Primary cells of myeloid and lymphoid } \\
\text { origin, } \\
\text { Bone marrow, human THP-1 cells, B } \\
\text { cells, human cervical cancer cell line }\end{array}$ & Cytoplasm/nucleus & $\begin{array}{l}23 \text { NLR genes in human } \\
\text { genome, } \\
34 \text { NLR genes in mice } \\
\text { genome }\end{array}$ & $\begin{array}{l}\text { Harton et al., } \\
\text { 2002; Inohara } \\
\text { and Nuñez, } 2003\end{array}$ \\
\hline TLRs & TLR5 & $\begin{array}{l}\text { Leucine-rich repeat } \\
\text { domain }\end{array}$ & $\begin{array}{l}\text { Membrane of Gram-negative bacteria, } \\
\text { Membrane of endosomal lysosomal } \\
\text { compartment }\end{array}$ & $\begin{array}{l}\text { Plasma membrane/ } \\
\text { intracellular } \\
\text { compartment }\end{array}$ & $\begin{array}{l}10 \text { TLR genes in human } \\
\text { genome, } \\
12 \text { TLR genes in mice } \\
\text { genome }\end{array}$ & Kouli et al., 2019 \\
\hline RLRs & MDA5 & $\begin{array}{l}\text { Carbohydrate } \\
\text { recognition domain }\end{array}$ & Low levels in resting cells & Cytoplasm & Unknown & $\begin{array}{l}\text { Dixit and Kagan, } \\
\text { 2013; Yoneyama } \\
\text { and Fujita, } 2009\end{array}$ \\
\hline CLRs & Dectin-1 & $\begin{array}{l}\text { C-type lectin-like } \\
\text { domain }\end{array}$ & primary expressed in myeloid cells & Cytoplasm & Unknown & $\begin{array}{l}\text { Dambuza and } \\
\text { Brown, } 2015\end{array}$ \\
\hline
\end{tabular}

of CrmA-dependent nuclear export, was used to stimulate cells (Benko et al., 2010; Meissner et al., 2010). Generally speaking, NLRC5 is mainly located in the cytoplasm when its expression is promoted. On the contrary, NLRC5 with physiological expression is often located in the nucleus.

\section{BIOLOGICAL FUNCTIONS}

\section{NLRC5's Role in Immune Responses}

Antiviral Immune Response

There is growing evidence that members of the NLRs family play a key role in antiviral responses. In fact, NLRC5 was demonstrated to be the last prosecutor of NLRs in the presence of virus invasion (Lupfer and Kanneganti, 2013). It was also reported that NLRC5 was involved in the modulation of innate antiviral immune response. For instance, it has been demonstrated that NLRC5 effectively prevents viral infection by inhibiting the activation of RIG-I and MDA5 as well as the production of type I IFN (Lupfer and Kanneganti, 2013; Mehraj et al., 2013). The expression of NLRC5 was increased in the STAT1 dependent manner after being stimulated by IFN-b or IFN-c (Wu et al., 2017). Nonetheless, many cell lines and primary human fibroblasts that have knocked out the NLRC5 gene exhibited a significant decrease of IFN-a/b levels after virus stimulation. This finding suggested that NLRC5 may obviously enhance antiviral signaling (Ranjan et al., 2015). For another, Kumar H et al. found

TABLE 2 | The expression of NLRC5 in various species influenced by inflammation.

\begin{tabular}{|c|c|c|c|c|}
\hline Species & Tissues/Cells & $\begin{array}{l}\text { Upregulated/ } \\
\text { Downregulated }\end{array}$ & Pathways & Author, Year \\
\hline Chicken & Macrophages & Upregulated & IFNA and IFNB & Lian et al., 2012 \\
\hline Mice & Peritoneal macrophages & Upregulated & $\mathrm{NF}-\kappa \mathrm{B} / \mathrm{IFN}-1$ & Tong et al., 2012 \\
\hline Mice & RAW264.7 & Upregulated & JAK2/STAT3 & Li et al., 2014 \\
\hline Chicken & Spleen & Upregulated & $\mathrm{NF}-\mathrm{\kappa B}$ & Chang et al., 2015 \\
\hline Human & LX-2 cells & Upregulated & $\mathrm{NF}-\kappa \mathrm{B} / \mathrm{Smad} 3$ & Xu et al., 2015 \\
\hline Human & HCC tissues and cells & Upregulated & AKTNEGF-A & He et al., 2016 \\
\hline Human & Cervical cells & Upregulated & $\mathrm{MiR} / \mathrm{NF}-\kappa \mathrm{B}$ & Li et al., 2016a; Li et al., 2016b \\
\hline Mice & HSC cells & Upregulated & $\mathrm{NF}-\kappa \mathrm{B}$ & Liu et al., 2016 \\
\hline Human & Keloid fibroblasts & Upregulated & TGF- $\beta 1 / \mathrm{Smad}$ & Ma et al., 2016 \\
\hline Human & HCC tissues and cells & Upregulated & Wnt/ $\beta$-catenin & Peng et al., 2016 \\
\hline Fish & Atlantic Salmon & $\begin{array}{l}\text { Upregulated or } \\
\text { Downregulated }\end{array}$ & $\begin{array}{l}\text { NLRC5 } \\
\text { inflammasome }\end{array}$ & Pontigo et al., 2016 \\
\hline Chicken & Embryo fibroblasts & Downregulated & MHC-I & Qiu et al., 2016 \\
\hline Mice & Liver tissues and HSC & Upregulated & $N F-\kappa B$ & Xu et al., 2016 \\
\hline Rat & FLSs & Upregulated & $N F-\kappa B$ & Liu et al., 2017b \\
\hline Fish & Zebrafish & Upregulated & IFN-1 & Wu et al., 2017 \\
\hline Fish & Rainbow trout & $\begin{array}{l}\text { Upregulated or } \\
\text { Downregulated }\end{array}$ & unknown & Alvarez et al., 2017 \\
\hline Mice & Cardiac muscle cells & Downregulated & TLR4/NF-кB & Ma and Xie, 2017 \\
\hline Rat & Cardiac fibroblasts & Upregulated & TGF- $\beta 1 /$ Smad3 & Zhou et al., 2017 \\
\hline Human & $\mathrm{HK}-2$ & Upregulated & PI3K/AKT & Han et al., 2018 \\
\hline Mice & Hepatocyte & Upregulated & Noncoding RNA & Wang et al.,2018 \\
\hline Human & Renal biopsy samples & Upregulated & TGF- $\beta 1 / \mathrm{Smad}$ & Wang et al., 2018 \\
\hline Human & Blood samples & Downregulated & Methylation & Zeng et al., 2018 \\
\hline
\end{tabular}


that cytokines production of macrophages and DCs are not affect by virus, HSV-1, or polyI:C infection (Kumar et al., 2011). At present, the antiviral immune response of NLRC5 is still unclear, and further studies are needed to reveal the potential mechanism.

\section{Inflammatory Immune Response}

NLRs could recognize intracellular pathogens and promote the expression of pro-inflammatory cytokines. A great number of studies have suggested that NLRC5 is widely expressed in immune tissues, lymphocytes, and macrophages/monocytes (Benko et al., 2010; Lian et al., 2012). Furthermore, NLRC5 could play an important role in the regulation of inflammatory pathways (Ciraci et al., 2010; Davis et al., 2011; Pacifico and Davis, 2016). For example, NLRC5 shields T lymphocytes from NK-cell-mediated elimination under inflammatory conditions (Ludigs et al., 2016). It was generally reported that NLRC5 plays an active role in the first stage of inflammation. While the importance of NLRC5 was gradually diminished with the process of inflammation (Null, 2003). Collectively, NLRC5 was an indicator that may be used as a biomarker for inflammatory disease in clinical practice.

\section{NLRC5's Genotype in Inflammatory Immune Responses}

It is well known that genetic background has an effect on gene expression (Williams et al., 2007). The NLRC5 gene is located at $16 q 13$, which is a leucine-rich repeat sequence that made up of 49 exons (94kpb) (Zupin et al., 2017). Zupin et al. also found that the rs289723, located in NLRC5 gene, was closely associated with an increased risk of chronic mild periodontitis and chronic local periodontitis. Periodontitis is a typical inflammatory disease that involves complex pathological processes (Pihlstrom et al., 2005). It was also found that the rs28972A/A genotype of NLRC5 was highly associated with susceptibility to chronic mild and chronic local periodontitis. The previous studies have shown that about 20 genes were involved in the activation of inflammation (Blander and Sander, 2012). In addition, Marth et al. found that the expression of the NLRC5 increased significantly within 3 hours in response to the introduction of E. coli. And this finding also indicated that the introduction of E. coli into the uterus of healthy animal has an effect on inducing inflammation, which was an effective model of innate immunity as well (Marth et al., 2016). Moreover, numerous studies have provided evidence that common variations in the NLR genes were highly correlated to the incidence of intestinal inflammation as well as susceptibility to cancer (Ogura et al., 2001; Villani et al., 2009; Kutikhin, 2011; Jostins et al., 2012). These findings may give us a hint that more immune diseases are closely related to NLRC5 gene phenotype and expression.

\section{NLRC5's Role in Liver Diseases Liver Fibrosis}

NLRC5 is widely expressed in the liver tissues and has recently been recognized as an active regulator of NF- $\kappa \mathrm{B}$ signaling pathways (Cui et al., 2010; Tong et al., 2012; Zhang et al., 2019). It has been reported that NF- $\kappa B$ could effectively modulates hepatic fibrogenesis by regulating hepatocyte injury, inflammatory signals, and fibrogenic responses (Luedde and Schwabe, 2011). Furthermore, there is increasing evidence that NLRC5 plays a key role in the development and reversal of hepatic fibrosis. Liu et al. found that the expression of NLRC5 increased during the development of liver fibrosis and decreased during the reversal stage. Besides, enforced expression of NLRC5 dramatically could inhibit the fibrosis recovery, while knockdown of NLRC5 promoted the fibrosis recovery (Liu et al., 2016). Xu et al. found that the expression of NLRC5 increased significantly in fibrotic liver tissues of human, and several components of NLR inflammasome were also found to be increased (Gressner et al., 2002). An apparently increased expression of NLRC5 in HSC was observed after being stimulated by TGF- $\beta 1$, which is known as a potent stimulus for HSC-induced fibrogenesis (Xu et al., 2016). Collectively, NLRC5 may take an active part in the occurrence and reversal of hepatic fibrosis. These findings also provide essential proof of the principle that NLRC5 may represent a target for the prevention or treatment of liver fibrosis.

\section{Hepatocellular Carcinoma}

Pattern recognition receptors (PRRs) are innate immunity sensors that performed a pivotal role in the modulation of tumor immunity. They could identify danger signals, clean the profitless cells, and balance the quantity of the host flora to thereby modulate the tumor immunity. In addition, PPRs were also found to facilitate tumorigenesis by reducing the population of regulatory cell and inducing the immunosuppressive cytokines (Zaki et al., 2011; Pradere et al., 2014). A lot of members of NLRs have been demonstrated to participate in tumor genesis as well (Hugot et al., 2001; Da Silva Correia et al., 2006; Ohno et al., 2008; Villani et al., 2009; Zaki et al., 2011; Burdette et al., 2012). What's more, increasing number of studies also reported that NLRC5 was involved in the development of keloid disease, human papillomavirus, human prostate cancer, and gastric cancer (Castano-Rodriguez et al., 2014; Carretero et al., 2016; Li et al., 2016a; Ma et al., 2016). Of note, the expression of NLRC5 was higher in HCC tissues than in normal tissues. Basic experiments research suggested that silencing NLRC5 could subsequently inhibit HCC cells proliferation, migration, invasion, and tumor formation. Conversely, enforced expression of NLRC5 could facilitate the proliferation, migration, and invasion of HCC cells (Peng et al., 2016). He et al. also found that NLRC5 was expressed highly in clinical samples of HCC patients. Taken together, NLRC5 may become a favorable option for treating HCC by inhibiting cancer metastasis and proliferation. (He et al., 2016).

\section{Liver Inflammatory Injury}

Accumulating evidence showed that persistent inflammation leads to liver injury and continuous activation of hepatic stellate cells (HSC) will make liver injury worsen. It is generally known that HSC can be activated and transformed into myofibroblastlike cells. Damage to hepatocytes and Kupffer are commonly acknowledged as the first-line effects during the activation of quiescent HSC (Allen, 2011; Mormone et al., 2011). It was also 
demonstrated that the level of NLRC5 expression could act as an indicator of inflammation severity. TNF- $\alpha$, a super innate immune activator, could significantly increase the expression of NLRC5 in HSC (Fan et al., 2013; Koppula et al., 2013). Besides, Li et al. found that NLRC5 expression could be quickly induced by LPS. Also, they hypothesized that NLRC5 may play a pivotal role in LPS-induced cytokine secretion of hepatic macrophages (Li et al., 2014). Furthermore, Xu et al. also found that NLRC5 is responsible for inflammatory cytokine expression by promote the secretion of inflammatory factors in LX-2 cells (Xu et al., 2015). In conclusion, these findings suggested that the regulation of NLRC5 expression may be of great significance in the treatment of inflammatory liver injury.

\section{Hepatic Steatosis}

A large number of studies have shown that hepatic steatosis is a key event in the process of liver injury induced by EtOH. Alcoholic steatosis is one of the major causes of alcoholic liver disease (Bieghs et al., 2013). Alcoholic liver disease (ALD) is a worldwide common disease with high morbidity and mortality, which is closely associated with excessive alcohol consumption (Ricieri Brito et al., 2010; Dubuquoy, 2016; Zhang et al., 2018). Functional studies have suggested that NLRC5 could positively regulate ethanol-induced hepatic steatosis. Wang et al. reported that the expression of NLRC5 increased significantly in EtOHfed mice, and it also may be involved in the pathogenesis of EtOH-induced hepatic steatosis (Wang et al., 2018b).

\section{Liver Ischemia/Reperfusion Injury}

Ischemia reperfusion injury (IRI) of liver is an unavoidable clinical event during liver surgery, such as hepatectomy, hypovolemic shock, and liver transplantation (Aldrighetti et al., 2006; Linares et al., 2018; Zhong et al., 2018). A large number of inflammatory cytokines were released in the process of liver ischemia/reperfusion injury, and then they can quickly lead to hepatocyte damage (Van Golen et al., 2013). Given that NLRC5 plays an important role in the regulation of inflammation, it may also be involved in the regulation of liver ischemia/reperfusion injury. Chen et al. reported that NLRC5-deficient mice developed severe liver damage and inflammatory response after I/R surgery (Chen et al., 2017). In short, these findings suggested that NLRC5 may play a vital role in alleviating liver I/R injury (Figure 1).

\section{NLRC5's Role in Renal Diseases Renal Fibrosis}

Renal fibrosis is considered to be a representative pathological character in the development of chronic renal disease, which is a worldwide public health event with high mortality (Levey et al., 2007; Liu, 2011). It is characterized by the accumulation and deposition of extracellular matrix (ECM) proteins, which mainly caused by the increase of myofibroblasts (Strutz and Zeisberg, 2006). One study has shown that NLRC5 could act as a fibrogenic molecule, which involves in the occurrence and development of fibrosis diseases (Xu et al., 2016). Besides, Wang et al. found

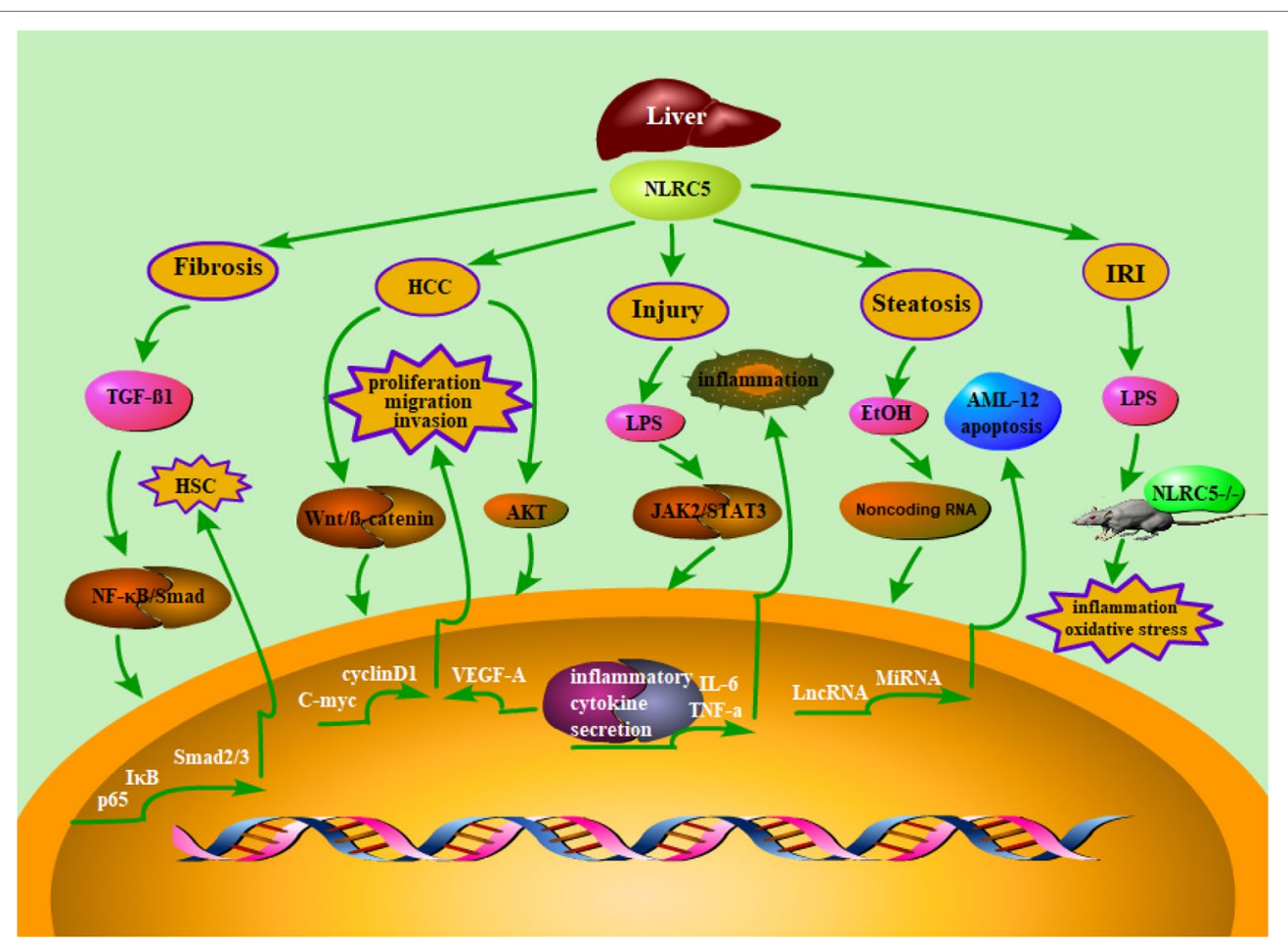

FIGURE 1 | Schematic representation of NLRC5's role in liver diseases. Accumulating evidence suggested that NLRC5 has been linked to a lot of liver diseases, such as liver fibrosis, hepatocellular carcinoma, liver inflammatory injury, hepatic steatosis, and Liver ischemia/reperfusion injury. Moreover, it has been demonstrated that NLRC5 plays an essential role in regulating relevant mechanisms of liver diseases. Herein, we summarized the NLRC5-relevant signaling pathways, which were involved in liver diseases. 
that the expression of NLRC5 increased significantly in renal fibrosis tissues and cells. Knockout of NLRC5 dramatically could inhibit the proliferation of renal fibrosis cells and decrease the accumulation of ECM (Wang et al., 2018c). These findings strongly support the view that NLRC5 participate in the pathogenesis of renal fibrosis and can also be treated as a therapeutic target.

\section{Acute Kidney Injury}

Acute kidney injury is a common clinical complication, which is mainly caused by renal ischemia-reperfusion (I/R) injury (Fanelli et al., 2018; Lazzeri et al., 2018; Wang et al., 2018a). Tubular epithelial cell injury is the most prominent feature of acute renal injury (Liu et al., 2015). Exposure of human renal tubular epithelial cells (HK-2) to H/R is a classic model of renal I/R injury model for study in vitro. Han et al. found that NLRC5 is highly expressed in HK-2 cell of H/R injury model. It has also been shown that silencing NLRC5 obviously increased the viability of H/R injury HK-2 cell, inhibited the apoptosis of renal $\mathrm{I} / \mathrm{R}$ injury cell and promoted the recovery of renal I/R injury (Han et al., 2018). Quanxin Li and colleagues identified that serum creatinine and renal tubule injury were significantly reduced in the renal I/R injury of NLRC5 defective mice. Their results strongly support the hypothesis that NLRC5 plays a leading role in renal I/R injury. Therefore, the regulation of NLRC5-mediated pathway may be of great significance in the treatment of acute renal injury (Li et al., 2018b). In addition, these studies also indicated that acute kidney injury can be reversed by downregulating the expression of NLRC5.

\section{Diabetic Nephropathy}

Diabetic nephropathy (DN) is one of the major causes of advanced nephropathy and has become a worldwide public health problem (Saran et al., 2017; Li et al., 2018a; Mathur et al., 2018). Pathological characteristics of DN include oxidative stress, inflammatory responses, and metabolic dysfunction, while the exact pathogenesis are complex and still remain to be further investigated (Wada and Makino, 2016). Recent studies have reported that innate immunity plays an essential role in the pathogenesis of DN (Navarro-Gonzalez et al., 2011). In addition, NLRC5 is demonstrated to participate in the occurrence and development of DN (Luan et al., 2018). It has been demonstrated that NLRC5 is highly expressed in DN. And knocking out of NLRC5 could promote the recovery of kidney injury in diabetic mice. These studies suggested that NLRC5 plays an important role in inflammatory responses and fibrosis development, which could make diabetic kidney deteriorate. These findings also emphasize the importance of NLRC5 in the progression of diabetic nephropathy. Therefore, down-regulating the expression of NLRC5 is a potential approach for DN treatment by alleviating inflammatory response (Figure 2).

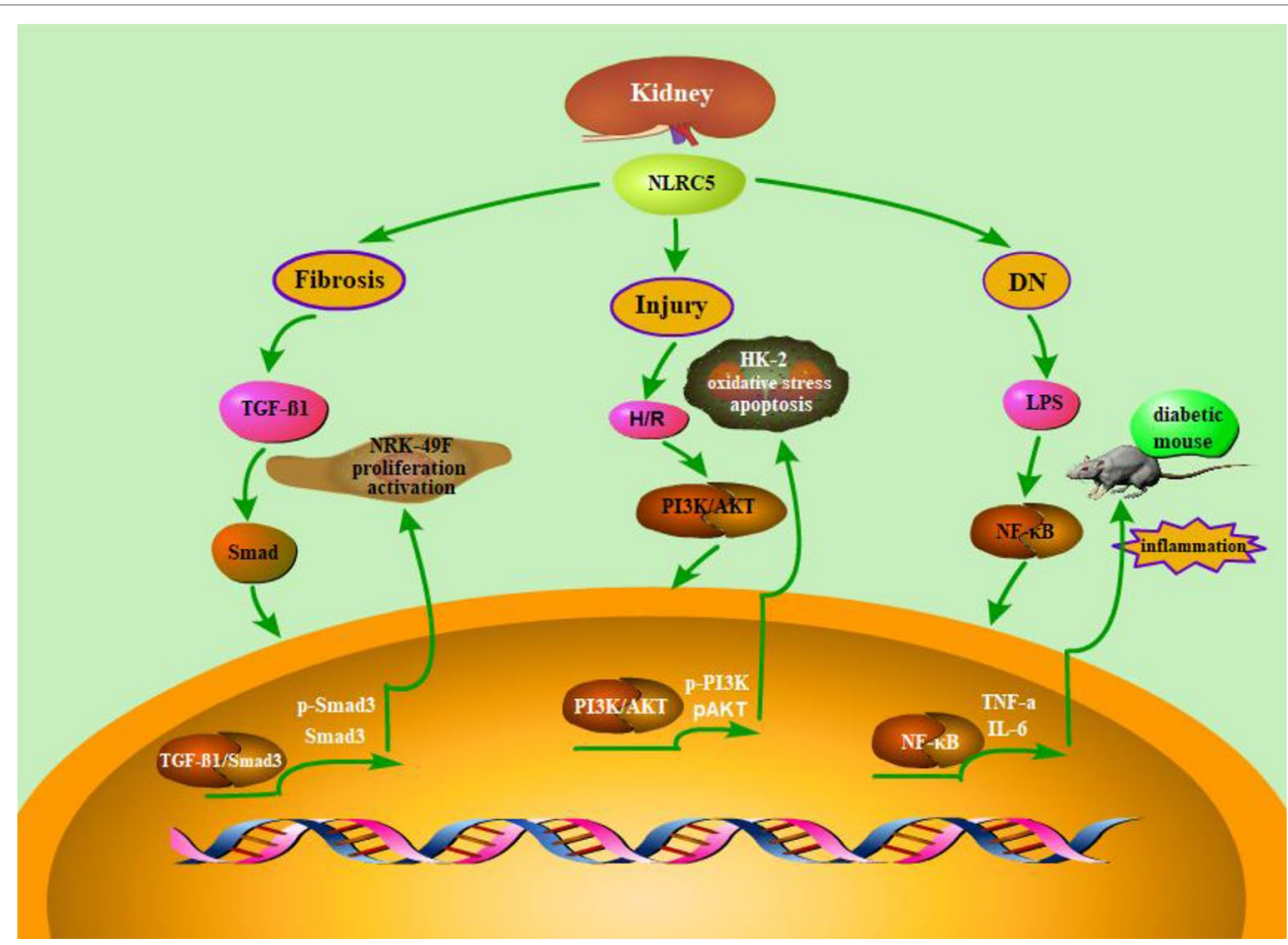

FIGURE 2 | Schematic representation of NLRC5's role in renal diseases. As is described in the above content, NLRC5 is widely expressed in renal related tissue and has also been demonstrated to involve in a variety of kidney diseases for and wide. A number of functional studies have reported that Up-regulation or downregulation of NLRC5 may play a key role in the underlying pathogenesis of renal disease. For instance, knock out of NLRC5 could inhibit the proliferation of renal fibrosis cells and decrease the accumulation of ECM. Besides, RNA interference-mediated Knock down of NLRC5 attenuates renal I/R injury in vitro through the activation of PI3K/Akt signaling pathway. 


\section{NLRC5's Role in Rheumatoid Arthritis}

Rheumatoid arthritis (RA) is a chronic autoimmune disease, which could eventually cause joint deformities and disability (Rossato et al., 2015; Zhang et al., 2015; Zhang et al., 2016a). Fibroblast-like synoviocytes (FLSs) are at the junction of the joint and the abnormal proliferation of FLSs is a central factor in the progression of RA (Jia et al., 2016; Li et al., 2016b). IL-17 is commonly considered to be a key proinflammatory cytokine in RA pathogenesis (Buckland, 2010). It has also been reported that IL-17 participated in the pathogenesis of inflammatory diseases through the NLRP3-mediated inflammasome pathways (Cho et al., 2012; Chi et al., 2017). Besides, previous studies have shown that NLRs are wildly expressed in RA, and they also play an important role in inflammatory response (Theofilopoulos et al., 2010; Takakubo and Konttinen, 2012). Since NLRs involve in inflammatory diseases and promote the clearance of invasive pathogens, it may also be involved in the progress of RA. It is well known that Animal model of Adjuvant arthritis (AA) is a typical model for studying RA (Liu et al., 2017a; Sun et al., 2017). Liu et al. found that NLRC5 is highly expressed in AA rat animal. Moreover, RNA interference-mediated Knock down of NLRC5 could significantly inhibit the proliferation of FLSs and reduce the expression of inflammatory cytokine (Liu et al., 2017b). And thus, NLRC5 may be a potential therapeutic target for the treatment of RA. For instance, we can effectively inhibit the RA progression by regulating the expression of NLRC5.

\section{NLRC5's Role in Heart Diseases}

Cardiac fibrosis is one of the most obvious pathological characteristics of myocardial remodeling in heart diseases, which has a high morbidity and mortality (Krenning et al., 2010; Burlew and Weber, 2014). Because of its complexity and multifactor, the molecular mechanism of myocardial fibrosis remains to be further illuminated (Brilla et al., 2000; Spinale et al., 2000; Leask, 2010). The major pathological features of cardiac fibrosis are rapid proliferation of CFs and excessive deposition of extracellular matrix (ECM) (Porter and Turner, 2009). Zhou et al. found that NLRC5 was highly expressed in TGF- $\beta 1$-induced CFs (Zhou et al., 2017). Recent advance have also found that silencing NLRC5 could significantly inhibit proliferation, ECM deposition, and pro-fibrotic molecules expression in CFs (Yang et al., 2019). These results initially suggested that NLRC5 has a regulatory effect on accelerating myocardial fibrosis, which involves in heart disease. Therefore, down regulating the expression of NLRC5 may be useful to alleviate myocardial fibrosis. For another, Ma et al. reported that a high-fat diet can lead to myocardial injury, which was particularly evident in mice with the NLRC5 deficiency (Ma and Xie, 2017). They also found that the deficiency of NLRC5 increased the expression of fibrosisrelated proteins. At the same time, the study of cardiac function markers also indicated that NLRC5 knock out obviously induced heart dysfunction. In conclusion, these evidences indicated that the level of NLRC5 expression is closely related to heart disease. Indeed, further exploratory and validation research are urgently needed to illustrate the substantial link between NLRC5 and heart disease.

\section{NLRC5's Role in Lung and Spleen Diseases}

The gene of human NLRC5 is highly expressed in lung and spleen (Biswas et al., 2012; Yao and Qian, 2013). NLRC5 is famous as a transactivator of MHC class I and also plays a central role in tumor immune escape through regulation of MHC class I (Garcia-Lora et al., 2003; Staehli et al., 2012; Li et al., 2019). Li et al. investigated the role of NLRC5 in patients with stage III non-small-cell lung cancer (NSCLC) (Li et al., 2015). They found that NLRC5 is highly expressed in NSCLC tissues. Since decreased nuclear expression of NLRC5 is related to the loss of MHC class I heavy chain, NLRC5 also be considered as a prognostic indicator and a predictor of survival in NSCLC patients (Bijen et al., 2010). And thus, the level of NLRC5 expression could be used to calculating the survival of NSCLC patients. Besides, Guo et al. found that upregulation of NLRC5 induced airway epithelial cell proliferation. Triantafilou et al. also found that virus infection in primary bronchial cells significantly induced the expression of NLRC5 (Triantafilou et al., 2013; Guo et al., 2015). Chang et al. reported that the mutation of NLRC5 promoter was involved in the modulation of related signaling pathways after chicken spleen infection (Chang et al., 2015). Indeed, our understanding of NLRC5' role in lung and spleen diseases is extremely poor and remains to be improved.

\section{REGULATION MECHANISM}

\section{The Methylation of NLRC5}

It has been reported that DNA methylation plays an important role in genomic dynamics, which is closely related with development of various diseases. It may change at any one site, and thus affect many biological processes of human disease (Bernstein et al., 2007; Feinberg, 2007; Lister et al., 2009). An accurate and in-depth understanding of the DNA methylation status of genes is essential to uncover the underlying DNA methylation mechanism and pathogenic mechanism (Li et al., 2010). Besides, it is also known that methylation of NLRC5 is negatively correlated with MHC class I gene expression. Furthermore, the expression of NLRC5 is demonstrated to be regulated by NLRC5 methylation (Guo et al., 2016). Zeng et al. investigated the NLRC5 methylation sites and status in the genome of centenarians and subsequently indicated that hypomethylation of NLRC5 are highly correlated with age in centenarians (Zeng et al., 2018). Previous studies found that the degree of NLRC5 methylation is negatively correlated with NLRC expression in a variety of cells (Yoshihama et al., 2016; Yoshihama et al., 2017). Zhang et al. found that HIV infection can lead to lower methylation of NLRC5, suggesting that NLRC5 plays an important role in the pathogenesis of HIV (Zhang et al., 2016b). Taken together, these evidences indicated that NLRC5 methylation plays a key role in immune diseases by regulating multiple biological pathways, and it could act as a promising biomarker as well.

\section{NLRC5 Inflammasome}

The formation of NLRC5 inflammasome is of great importance to recognize pathogens, activate inflammatory caspases, 
and modulate host defence response (Martinon et al., 2009). Davis et al. thought that NLRC5 could form inflammasome in combination with NLRP3 in the presence of pathogens (Davis et al., 2011). It has been revealed that RNA interference-mediated knockdown of NLRC5 significantly decrease caspase 1 , IL-1 $\beta$, and IL-18 expression, which are response to pathogens infection. Therefore, they hold the view that NLRC5 is an indispensable component in the secretion of inflammasome dependent inflammatory cytokine. It has also been suggested that NLRC5 cooperates with NLRP3 to reconstitute inflammasome activity in an ectopic system (Ting and Davis, 2005). Besides, NLRC5 is widely expressed in tissues with bacterial and viral infections, and it can also induce expression of inflammasome-related proteins (Livak and Schmittgen, 2001). It was also reported that NLRC5 inflammasome involves in parr and smolt stage of Atlantic salmon. To sum up, these studies suggested that NLRC5 may be involved in the regulation of immune disease by the way of forming a functional inflammasome.

\section{Signaling Pathways}

$\mathrm{NF}-\kappa \mathrm{B}$ is considered to be one of the most important transcription factors associated with inflammatory diseases. It is known that $\mathrm{NF}-\kappa \mathrm{B}$ and type I interferon signaling pathways could be directly regulated by themselves through the modulation of feedback loops (Komuro et al., 2008). NLRC5 plays a regulatory role in inflammatory response, innate immune response, and antiviral response. It was reported that NLRC5 could combine with RIG-I and MDA5 to encompass IFN-I pathway. In short, NLRC5 has been demonstrated to play a pivotal role in activating type I interferon signaling pathways. Of course, in one way, IFN- $\gamma$ could regulate the promoter of NLRC5 and its gene product. For another, NLRC5 is considered as a mediator that could positively or negatively regulate IFN, NF- $\kappa \mathrm{B}$ signaling pathways. (Cui et al., 2010). They found that NLRC5 inhibited the phosphorylation of IKK and frustrated the activation of NF- $\kappa$ B. Furthermore, some studies also suggested that RNA interference-mediated knockdown of NLRC5 significantly enhanced the signaling of $\mathrm{NF}-\kappa \mathrm{B}$ and type I IFN in mice. On the contrary, multiple studies implicated that NLRC5 positively regulated NF- $\kappa$ B and IFN-I pathways. For instance, knockdown of NLRC5 lead to reduced signaling of NF- $\mathrm{KB}$ and type I IFN, and up-regulating the expression of NLRC5 promoted IKK and IRF3 phosphorylation followed by activation of NF- $\kappa B$ (Neerincx et al., 2012; Tong et al., 2012). In addition, NLRC5 could modulate immune response through many signaling pathways that have already been confirmed to participate in the occurrence and development of immune diseases for and wide. Meissner et al. found that NLRC5 significantly increased the expression of MHC class I by activating the promoters of MHC class I genes (Meissner et al., 2010). Li et al. also found that NLRC5 induced the secretion of the inflammatory cytokine through JAK2/STAT3 signaling pathway (Li et al., 2014). It has been reported that NLRC5 promoted the cell proliferation, which is likely to be mediated

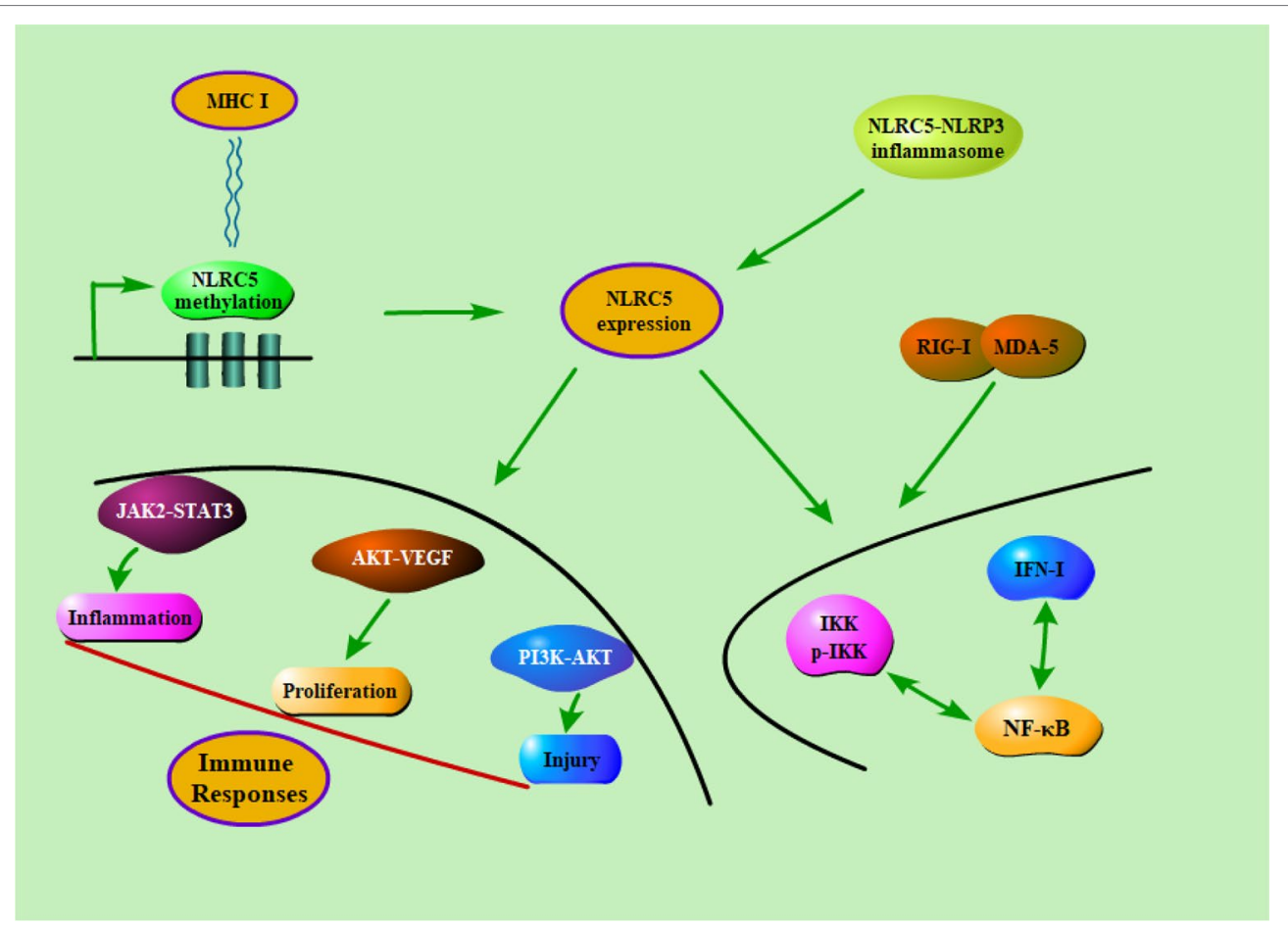

FIGURE 3 | The potential regulatory mechanisms of NLRC5 in immune diseases. Firstly, the methylation of NLRC5 were negatively correlated with MHC class I gene expression. Secondly, NLRC5 could form inflammasome in combination with NLRP3 in the presence of pathogens. Finally, NLRC5 could modulate immune response through a series of signaling pathways that have already been confirmed to participate in the occurrence and development of immune diseases for and wide. 
by the AKT/VEGF-A pathway (He et al., 2016). Han et al. also demonstrated that NLRC5 could accelerate renal I/R injury by activating PI3K/AKT signaling pathway (Han et al., 2018). In short, these findings indicated that NLRC5 was involved in the occurrence and development of immune disease through regulation of diverse signaling pathways (Figure 3).

\section{CONCLUDING REMARKS}

As reviewed above, the diverse characters of NLRC5 have been introduced and summarized. In addition, recent advance about immanent characteristics, biological function of NLRC5 and molecular mechanisms of NLRC5-mediated immune diseases are also discussed. In the past decades of years, researchers have made much progress in characterizing the NLRC5 crystal structure and detecting the expression of NLRC5 in tissues and cells of immune disease. The fact that NLRC5 plays an essential role in the control of the regulatory mechanism has made it a promising therapeutic target for immune disease. The role of NLRC5, however, still remains controversial in innate immunity and relevant signaling pathways. In a word, the relevant pathways of NLRC5 in innate immunity have not yet been elucidated clearly so far and more experimental investigations about how NLRC5

\section{REFERENCES}

Akira, S., Uematsu, S., and Takeuchi, O. (2006). Pathogen recognition and innate immunity. Cell 124, 783-801. doi: 10.1016/j.cell.2006.02.015

Aldrighetti, L., Pulitano, C., Arru, M., Finazzi, R., Catena, M., Soldini, L., et al. (2006). Impact of preoperative steroids administration on ischemia-reperfusion injury and systemic responses in liver surgery: a prospective randomized study. Liver Transpl. 12, 941-949. doi: 10.1002/lt.20745

Allen, I. C. (2011). A NOD to zebrafish models of inflammatory bowel disease pathogenesis. Dis. Model Mech. 4, 711-712. doi: 10.1242/dmm.008805

Alvarez, C. A., Ramirez-Cepeda, F., Santana, P., Torres, E., Cortes, J., et al. (2017). Insights into the diversity of NOD-like receptors: identification and expression analysis of NLRC3, NLRC5 and NLRX1 in rainbow trout. Mol. Immunol. 87, 102-113. doi: 10.1016/j.molimm.2017.03.010

Benko, S., Magalhaes, J. G., Philpott, D. J., and Girardin, S. E. (2010). NLRC5 limits the activation of inflammatory pathways. J. Immunol. 185, 1681-1691. doi: 10.4049/jimmunol.0903900

Bernstein, B. E., Meissner, A., and Lander, E. S. (2007). The mammalian epigenome. Cell 128, 669-681. doi: 10.1016/j.cell.2007.01.033

Bertin, J., and DiStefano, P. (2000). The PYRIN domain: a novel motif found in apoptosis and inflammation proteins. Cell Death Differ. 7, 1273-1274. doi: 10.1038/sj.cdd. 4400774

Beutler, B. (2004). Inferences, questions and possibilities in Toll-like receptor signalling. Nature 430, 257-263. doi: 10.1038/nature02761

Bieghs, V., Hendrikx, T., Van Gorp, P. J., Verheyen, F., Guichot, Y. D., Walenbergh, S. M., et al. (2013). The cholesterol derivative 27-hydroxycholesterol reduces steatohepatitis in mice. Gastroenterology 144167-178, e161. doi: 10.1053/j. gastro.2012.09.062

Bijen, C. B., Bantema-Joppe, E. J., De Jong, R. A., Leffers, N., Mourits, M. J., Eggink, H. F., et al. (2010). The prognostic role of classical and nonclassical MHC class I expression in endometrial cancer. Int. J. Cancer 126, 1417-1427. doi: 10.1002/ijc. 24852

Birnbaum, M. J., Clem, R. J., and Miller, L. K. (1994). An apoptosis-inhibiting gene from a nuclear polyhedrosis virus encoding a polypeptide with Cys/His sequence motifs. J. Virol. 68, 2521-2528. performs in the host defense against pathogens and transmits immune signals are urgently needed in the future. Moreover, there are few studies on the role of NLRC5 in human immune diseases. Therefore, it is necessary to put on a deep insight on the relationship between the immune function of NLRC5 and human immune diseases. Besides, given that the swift development of molecular docking technology, more precise characterization of crystal deserved to be explored specifically. In summary, these promising properties of NLRC5 make it an appealing therapeutic target through regulating the expression of NLRC5 and NLRC5dependent signaling pathways.

\section{AUTHOR CONTRIBUTIONS}

J-QW, Y-RL, and JLi wrote the main manuscript text. QX and JLia prepared Figures 1-3. Q-RX and R-NC prepared Tables 1 and 2. All authors reviewed the manuscript.

\section{ACKNOWLEDGMENTS}

This project was supported by the National Natural Science Foundation of China (No. 81473268, No. 81770609).

Biswas, A., Meissner, T. B., Kawai, T., and Kobayashi, K. S. (2012). Cutting edge: impaired MHC class I expression in mice deficient for Nlrc5/class I transactivator. J. Immunol. 189, 516-520. doi: 10.4049/jimmunol.1200064

Blander, J. M., and Sander, L. E. (2012). Beyond pattern recognition: five immune checkpoints for scaling the microbial threat. Nat. Rev. Immunol. 12, 215-225. doi: $10.1038 /$ nri3167

Brilla, C. G., Funck, R. C., and Rupp, H. (2000). Lisinopril-mediated regression of myocardial fibrosis in patients with hypertensive heart disease. Circulation 102, 1388-1393. doi: 10.1161/01.CIR.102.12.1388

Buckland, J. (2010). New role for mast cells as IL-17-expressing effector cells in established RA. Nat. Rev. Rheumatol. 6, 243. doi: 10.1038/nrrheum.2010.50

Burdette, D., Haskett, A., Presser, L., Mcrae, S., Iqbal, J., and Waris, G. (2012). Hepatitis C virus activates interleukin-1beta via caspase-1-inflammasome complex. J. Gen. Virol. 93, 235-246. doi: 10.1099/vir.0.034033-0

Burlew, B. S., and Weber, K. T. (2014). Cardiac fibrosis as a cause of diastolic dysfunction. Herz 27, 92-98. doi: 10.1007/s00059-002-2354-y

Carretero, F. J., Del Campo, A. B., Flores-Martin, J. F., Mendez, R., GarciaLopez, C., Cozar, J. M., et al. (2016). Frequent HLA class I alterations in human prostate cancer: molecular mechanisms and clinical relevance. Cancer Immunol. Immunother. 65, 47-59. doi: 10.1007/s00262-015-1774-5

Castano-Rodriguez, N., Kaakoush, N. O., Goh, K. L., Fock, K. M., and Mitchell, H. M. (2014). The NOD-like receptor signalling pathway in Helicobacter pylori infection and related gastric cancer: a case-control study and gene expression analyses. PloS One 9, e98899. doi: 10.1371/journal.pone.0098899

Chang, G., Liu, X., Ma, T., Xu, L., Wang, H., Li, Z., et al. (2015). A mutation in the NLRC5 promoter limits NF-kappaB signaling after Salmonella Enteritidis infection in the spleen of young chickens. Gene 568, 117-123. doi: 10.1016/j.gene.2015.05.023

Chen, Z., Ding, T., and Ma, C. G. (2017). Dexmedetomidine (DEX) protects against hepatic ischemia/reperfusion (I/R) injury by suppressing inflammation and oxidative stress in NLRC5 deficient mice. Biochem. Biophys. Res. Commun. 493, 1143-1150. doi: 10.1016/j.bbrc.2017.08.017

Chi, H. H., Hua, K. F., Lin, Y. C., Chu, C. L., Hsieh, C. Y., Hsu, Y. J., et al. (2017). IL-36 signaling facilitates activation of the NLRP3 inflammasome and IL-23/ IL-17 axis in renal inflammation and fibrosis. J. Am. Soc. Nephrol. 28, 20222037. doi: 10.1681/ASN.2016080840 
Cho, K. A., Suh, J. W., Lee, K. H., Kang, J. L., and Woo, S. Y. (2012). IL-17 and IL-22 enhance skin inflammation by stimulating the secretion of IL-1beta by keratinocytes via the ROS-NLRP3-caspase-1 pathway. Int. Immunol. 24, 147158. doi: $10.1093 /$ intimm/dxr110

Ciraci, C., Tuggle, C. K., Wannemuehler, M. J., Nettleton, D., and Lamont, S. J. (2010). Unique genome-wide transcriptome profiles of chicken macrophages exposed to Salmonella-derived endotoxin. BMC Genomics 11, 545. doi: 10.1186/1471-2164-11-545

Cui, J., Zhu, L., Xia, X., Wang, H. Y., Legras, X., Hong, J., et al. (2010). NLRC5 negatively regulates the NF-kappaB and type I interferon signaling pathways. Cell 141, 483-496. doi: 10.1016/j.cell.2010.03.040

Da Silva Correia, J., Miranda, Y., Austin-Brown, N., Hsu, J., Mathison, J., Xiang, R., et al. (2006). Nod1-dependent control of tumor growth. Proc. Natl. Acad. Sci. U. S. A. 103, 1840-1845. doi: 10.1073/pnas.0509228103

Dambuza, I. M., and Brown, G. D. (2015). C-type lectins in immunity: recent developments. Curr. Opin. Immunol. 32, 21-27. doi: 10.1016/j.coi.2014.12.002

Davis, B. K., Roberts, R. A., Huang, M. T., Willingham, S. B., Conti, B. J., Brickey, W. J., et al. (2011). Cutting edge: NLRC5-dependent activation of the inflammasome. J. Immunol. 186, 1333-1337. doi: 10.4049/jimmunol.1003111

Dixit, E., and Kagan, J. C. (2013). Intracellular pathogen detection by RIG-Ilike receptors. Adv. Immunol. 117, 99-125. doi: 10.1016/B978-0-12-4105249.00004-9

Dubuquoy, L. (2016). Lipocalin 2 highlights the complex role of neutrophils in alcoholic liver disease. J. Hepatol. 64, 770-772. doi: 10.1016/j.jhep.2016.01.020

Fairbrother, W. J., Gordon, N. C., Humke, E. W., O'Rourke, K. M., Starovasnik, M. A., Yin, J. P., et al. (2001). The PYRIN domain: a member of the death domain-fold superfamily. Protein Sci. 10, 1911-1918. doi: 10.1110/ps.13801

Fan, G. W., Zhang, Y., Jiang, X., Zhu, Y., Wang, B., Su, L., et al. (2013). Antiinflammatory activity of baicalein in LPS-stimulated RAW264.7 macrophages via estrogen receptor and NF-kappaB-dependent pathways. Inflammation 36, 1584-1591. doi: 10.1007/s10753-013-9703-2

Fanelli, V., Cantaluppi, V., Alessandri, F., Costamagna, A., Cappello, P., Brazzi, L., et al. (2018). Extracorporeal CO removal may improve renal function of patients with ARDS and acute kidney injury. Am. J. Respir. Crit. Care Med. 198, 687-690. doi: 10.1164/rccm.201712-2575LE.

Feinberg, A. P. (2007). Phenotypic plasticity and the epigenetics of human disease. Nature 447, 433-440. doi: 10.1038/nature05919

Franchi, L., Warner, N., Viani, K., and Nuñez, G. (2009). Function of Nod-like receptors in microbial recognition and host defense. Immunol. Rev. 227, 106128. doi: 10.1111/j.1600-065X.2008.00734.x

Garcia-Lora, A., Algarra, I., and Garrido, F. (2003). MHC class I antigens, immune surveillance, and tumor immune escape. J. Cell Physiol. 195, 346-355. doi: $10.1002 /$ jcp. 10290

Gressner, A. M., Weiskirchen, R., Breitkopf, K., and Dooley, S. (2002). Roles of TGF-beta in hepatic fibrosis. Front. Biosci. 7, d793-d807. doi: 10.2741/A812

Guo, X., Liu, T., Shi, H., Wang, J., Ji, P., Wang, H., et al. (2015). Respiratory syncytial virus infection upregulates NLRC5 and major histocompatibility complex class I expression through RIG-I induction in airway epithelial cells. J. Virol. 89, 7636-7645. doi: 10.1128/JVI.00349-15

Guo, X. M., Liu, X. P., Chang, G. B., Xu, L., Bi, Y. L., Wang, H. Z., et al. (2016). Characterization of the NLRC5 promoter in chicken: SNPs, regulatory elements and CpG islands. Anim. Genet. 47, 579-587. doi: 10.1111/age.12450

Gutte, P. G., Jurt, S., Grutter, M. G., and Zerbe, O. (2014). Unusual structural features revealed by the solution NMR structure of the NLRC5 caspase recruitment domain. Biochemistry 53, 3106-3117. doi: 10.1021/bi500177x

Han, F., Gao, Y., Ding, C. G., Xia, X. X., Wang, Y. X., Xue, W. J., et al. (2018). Knockdown of NLRC5 attenuates renal I/R injury in vitro through the activation of PI3K/Akt signaling pathway. BioMed. Pharmacother. 103, 222227. doi: 10.1016/j.biopha.2018.04.040

Harton, J. A., Linhoff, M. W., Zhang, J., and Ting, J. P. (2002). Cutting edge: CATERPILLER: a large family of mammalian genes containing CARD, pyrin, nucleotide-binding, and leucine-rich repeat domains. J. Immunol. 169, 40884093. doi: 10.4049/jimmunol.169.8.4088

He, Y. H., Li, M. F., Zhang, X. Y., Meng, X. M., Huang, C., and Li, J. (2016). NLRC5 promotes cell proliferation via regulating the AKT/VEGF-A signaling pathway in hepatocellular carcinoma. Toxicology 359-360, 47-57. doi: 10.1016/j. tox.2016.06.012
Hugot, J. P., Chamaillard, M., Zouali, H., Lesage, S., Cézard, J. P., Belaiche, J., et al. (2001). Association of NOD2 leucine-rich repeat variants with susceptibility to Crohn's disease. Nature 411, 599-603. doi: 10.1038/35079107

Inohara, N., and Nuñez, G. (2001). The NOD: a signaling module that regulates apoptosis and host defense against pathogens. Oncogene 20, 6473-6481. doi: 10.1038/sj.onc. 1204787

Inohara, N., and Nunez, G. (2003). NODs: intracellular proteins involved in inflammation and apoptosis. Nat. Rev. Immunol. 3, 371-382. doi: 10.1038/ nri1086

Inohara, Chamaillard, Mcdonald, C., and Nunez, G. (2005). NOD-LRR proteins: role in host-microbial interactions and inflammatory disease. Annu. Rev. Biochem. 74, 355-383. doi: 10.1146/annurev.biochem.74.082803.133347

Janeway, C. A.Jr. , and Medzhitov, R. (2002). Innate immune recognition. Annu. Rev. Immunol. 20, 197-216. doi: 10.1146/annurev.immunol.20.083001.084359

Janeway, C. A. (1989). Approaching the asymptote? Evolution and revolution in immunology. Cold Spring Harb. Symp. Quant. Biol. 54, 1-13. doi: 10.1101/ SQB.1989.054.01.003

Jia, X., Wei, F., Sun, X., Chang, Y., Xu, S., Yang, X., et al. (2016). CP-25 attenuates the inflammatory response of fibroblast-like synoviocytes co-cultured with BAFF-activated CD4(+) T cells. J. Ethnopharmacol. 189, 194-201. doi: 10.1016/j.jep.2016.05.034

Jostins, L., Ripke, S., Weersma, R. K., Duerr, R. H., Mcgovern, D. P., Hui, K. Y., et al. (2012). Host-microbe interactions have shaped the genetic architecture of inflammatory bowel disease. Nature 491, 119-124. doi: 10.1038/nature11582

Kanneganti, T. D., Lamkanfi, M., and Nunez, G. (2007). Intracellular NOD-like receptors in host defense and disease. Immunity 27, 549-559. doi: 10.1016/j. immuni.2007.10.002

Komuro, A., Bamming, D., and Horvath, C. M. (2008). Negative regulation of cytoplasmic RNA-mediated antiviral signaling. Cytokine 43, 350-358. doi: 10.1016/j.cyto.2008.07.011

Koonin, E. V., and Aravind, L. (2000). The NACHT family - a new group of predicted NTPases implicated in apoptosis and MHC transcription activation. Trends Biochem. Sci. 25, 223-224. doi: 10.1016/S0968-0004(00)01577-2

Koppula, S., Kim, W. J., Jiang, J., Shim, D. W., Oh, N. H., Kim, T. J., et al. (2013). Carpesium macrocephalum attenuates lipopolysaccharide-induced inflammation in macrophages by regulating the NF-kappaB/IkappaB-alpha, Akt, and STAT signaling pathways. Am. J. Chin Med. 41, 927-943. doi: 10.1142/ S0192415X13500626

Kouli, A., Horne, C. B., and Williams-Gray, C. H. (2019). Toll-like receptors and their therapeutic potential in Parkinson's disease and $\alpha$-synucleinopathies. Brain Behav. Immun. 81, 41-51. doi: 10.1016/j.bbi.2019.06.042

Krenning, G., Zeisberg, E. M., and Kalluri, R. (2010). The origin of fibroblasts and mechanism of cardiac fibrosis. J. Cell Physiol. 225, 631-637. doi: 10.1002/ jсp. 22322

Kuenzel, S., Till, A., Winkler, M., Hasler, R., Lipinski, S., Jung, S., et al. (2010). The nucleotide-binding oligomerization domain-like receptor NLRC5 is involved in IFN-dependent antiviral immune responses. J. Immunol. 184, 1990-2000. doi: 10.4049/jimmunol.0900557

Kumar, H., Kawai, T., and Akira, S. (2009). Pathogen recognition in the innate immune response. Biochem. J. 420, 1-16. doi: 10.1042/BJ20090272

Kumar, H., Pandey, S., Zou, J., Kumagai, Y., Takahashi, K., Akira, S., et al. (2011). NLRC5 deficiency does not influence cytokine induction by virus and bacteria infections. J. Immunol. 186, 994-1000. doi: 10.4049/jimmunol.1002094

Kutikhin, A. G. (2011). Role of NOD1/CARD4 and NOD2/CARD15 gene polymorphisms in cancer etiology. Hum. Immunol. 72, 955-968. doi: 10.1016/j. humimm.2011.06.003

Lamkanfi, M., and Dixit, V. M. (2009). Inflammasomes: guardians of cytosolic sanctity. Immunol. Rev. 227, 95-105. doi: 10.1111/j.1600-065X.2008.00730.x

Lazzeri, E., Angelotti, M. L., Peired, A., Conte, C., Marschner, J. A., Maggi, L., et al. (2018). Endocycle-related tubular cell hypertrophy and progenitor proliferation recover renal function after acute kidney injury. Nat. Commun. 9, 1344. doi: 10.1038/s41467-018-03753-4

Leask, A. (2010). Potential therapeutic targets for cardiac fibrosis: TGFbeta, angiotensin, endothelin, CCN2, and PDGF, partners in fibroblast activation. Circ. Res. 106, 1675-1680. doi: 10.1161/CIRCRESAHA.110.217737

Levey, A. S., Atkins, R., Coresh, J., Cohen, E. P., Collins, A. J., Eckardt, K. U., et al. (2007). Chronic kidney disease as a global public health problem: approaches 
and initiatives - a position statement from Kidney Disease Improving Global Outcomes. Kidney Int. 72, 247-259. doi: 10.1038/sj.ki.5002343

Li, Y., Zhu, J., Tian, G., Li, N., Li, Q., Ye, M., et al. (2010). The DNA methylome of human peripheral blood mononuclear cells. PloS Biol. 8, e1000533. doi: 10.1371/journal.pbio.1000533

Li, L., Xu, T., Huang, C., Peng, Y., and Li, J. (2014). NLRC5 mediates cytokine secretion in RAW264.7 macrophages and modulated by the JAK2/STAT3 pathway. Inflammation 37, 835-847. doi: 10.1007/s10753-013-9804-y

Li, X., Guo, F., Liu, Y., Chen, H. J., Wen, F., Zou, B., et al. (2015). NLRC5 expression in tumors and its role as a negative prognostic indicator in stage III non-smallcell lung cancer patients. Oncol. Lett. 10, 1533-1540. doi: 10.3892/ol.2015.3471

Li, J., Yu, L., Shen, Z., Li, Y., Chen, B., Wei, W., et al. (2016a). miR-34a and its novel target, NLRC5, are associated with HPV16 persistence. Infect. Genet. Evol. 44, 293-299. doi: 10.1016/j.meegid.2016.07.013

Li, R., Cai, L., Tang, W.-J., Lei, C., Hu, C.-M., and Yu, F. (2016b). Apoptotic effect of geniposide on fibroblast-like Synoviocytes in Rats with Adjuvant-Induced Arthritis via Inhibiting ERK Signal Pathway In Vitro. Inflammation 39, 30-38. doi: 10.1007/s10753-015-0219-9

Li, A., Peng, R., Sun, Y., Liu, H., Peng, H., and Zhang, Z. (2018a). LincRNA 1700020I14Rik alleviates cell proliferation and fibrosis in diabetic nephropathy via miR-34a-5p/Sirt1/HIF-1alpha signaling. Cell Death Dis. 9, 461. doi: 10.1038/s41419-018-0527-8

Li, Q., Wang, Z., Zhang, Y., Zhu, J., Li, L., Wang, X., et al. (2018b). NLRC5 deficiency protects against acute kidney injury in mice by mediating carcinoembryonic antigen-related cell adhesion molecule 1 signaling. Kidney Int. 94, 551-566. doi: 10.1016/j.kint.2018.02.031

Li, P., Shen, Y., Cui, P., Hu, Y., Zhang, Y., Miao, F., et al. (2019). Neuronal NLRC5 regulates MHC class expression in Neuro-2a cells and also during hippocampal development. J. Neurochem. doi: 10.1111/jnc.14876

Lian, L., Ciraci, C., Chang, G., Hu, J., and Lamont, S. J. (2012). NLRC5 knockdown in chicken macrophages alters response to LPS and poly (I:C) stimulation. BMC Vet. Res. 8, 23. doi: 10.1186/1746-6148-8-23

Linares, I., Farrokhi, K., Echeverri, J., Kaths, J. M., Kollmann, D., Hamar, M., et al. (2018). PPAR-gamma activation is associated with reduced liver ischemiareperfusion injury and altered tissue-resident macrophages polarization in a mouse model. PloS One 13, e0195212. doi: 10.1371/journal.pone.0195212

Lister, R., Pelizzola, M., Dowen, R. H., Hawkins, R. D., Hon, G., Tonti-Filippini, J., et al. (2009). Human DNA methylomes at base resolution show widespread epigenomic differences. Nature 462, 315-322. doi: 10.1038/nature08514

Liu, X. J., Hong, Q., Wang, Z., Yu, Y. Y., Zou, X., and Xu, L. H. (2015). MicroRNA34a suppresses autophagy in tubular epithelial cells in acute kidney injury. Am. J. Nephrol. 42, 168-175. doi: 10.1159/000439185

Liu, X., Wu, Y., Yang, Y., Li, W., Huang, C., Meng, X., et al. (2016). Role of NLRC5 in progression and reversal of hepatic fibrosis. Toxicol. Appl. Pharmacol. 294, 43-53. doi: 10.1016/j.taap.2016.01.012

Liu, Y., Sun, Z., Xu, D., Liu, J., Li, X., Wu, X., et al. (2017a). Hesperidin derivative-11 inhibits fibroblast-like synoviocytes proliferation by activating Secreted frizzled-related protein 2 in adjuvant arthritis rats. Eur. J. Pharmacol. 794, 173183. doi: $10.1016 /$ j.ejphar.2016.10.004

Liu, Y. R., Yan, X., Yu, H. X., Yao, Y., Wang, J. Q., Li, X. F., et al. (2017b). NLRC5 promotes cell proliferation via regulating the NF-kappaB signaling pathway in Rheumatoid arthritis. Mol. Immunol. 91, 24-34. doi: 10.1016/j. molimm.2017.08.024

Liu, Y. (2011). Cellular and molecular mechanisms of renal fibrosis. Nat. Rev. Nephrol. 7, 684-696. doi: 10.1038/nrneph.2011.149

Livak, K. J., and Schmittgen, T. D. (2001). Analysis of relative gene expression data using real-time quantitative PCR and the 2[-Delta Delta C(T)] Method. Methods 25, 402-408. doi: 10.1006/meth.2001.1262

Luan, P., Zhuang, J., Zou, J., Li, H., Shuai, P., Xu, X., et al. (2018). NLRC5 deficiency ameliorates diabetic nephropathy through alleviating inflammation. FASEB J. 32, 1070-1084. doi: 10.1096/f.201700511RR

Ludigs, K., Jandus, C., Utzschneider, D. T., Staehli, F., Bessoles, S., Dang, A. T., et al. (2016). NLRC5 shields T lymphocytes from NK-cell-mediated elimination under inflammatory conditions. Nat. Commun. 7, 10554. doi: 10.1038/ncomms10554

Luedde, T., and Schwabe, R. F. (2011). NF-kappaB in the liver-linking injury, fibrosis and hepatocellular carcinoma. Nat. Rev. Gastroenterol. Hepatol. 8, 108118. doi: $10.1038 /$ nrgastro.2010.213
Lupfer, C., and Kanneganti, T. D. (2013). The expanding role of NLRs in antiviral immunity. Immunol. Rev. 255, 13-24. doi: 10.1111/imr.12089

Ma, S. R., and Xie, X. W. (2017). NLRC5 deficiency promotes myocardial damage induced by high fat diet in mice through activating TLR4/NF-kappaB. BioMed. Pharmacother. 91, 755-766. doi: 10.1016/j.biopha.2017.03.062

Ma, H. L., Zhao, X. F., Chen, G. Z., Fang, R. H., and Zhang, F. R. (2016). Silencing NLRC5 inhibits extracellular matrix expression in keloid fibroblasts via inhibition of transforming growth factor-betal/Smad signaling pathway. BioMed. Pharmacother. 83, 1016-1021. doi: 10.1016/j.biopha.2016.08.012

Marth, C. D., Firestone, S. M., Glenton, L. Y., Browning, G. F., Young, N. D., and Krekeler, N. (2016). Oestrous cycle-dependent equine uterine immune response to induced infectious endometritis. Vet. Res. 47, 110. doi: 10.1186/ s13567-016-0398-x

Martinon, F., Hofmann, K., and Tschopp, J. (2001). The pyrin domain: a possible member of the death domain-fold family implicated in apoptosis and inflammation. Curr. Biol. 11, R118-R120. doi: 10.1016/ S0960-9822(01)00056-2

Martinon, F., Mayor, A., and Tschopp, J. (2009). The inflammasomes: guardians of the body. Annu. Rev. Immunol. 27, 229-265. doi: 10.1146/annurev. immunol.021908.132715

Mathur, A., Pandey, V. K., and Kakkar, P. (2018). Activation of GSK3beta/betaTrCP axis via PHLPP1 exacerbates Nrf2 degradation leading to impairment in cell survival pathway during diabetic nephropathy. Free Radic. Biol. Med. 120, 414-424. doi: 10.1016/j.freeradbiomed.2018.04.550

Medzhitov, R. (2007). Recognition of microorganisms and activation of the immune response. Nature 449, 819-826. doi: 10.1038/nature06246

Mehraj, V., Textoris, J., Ben Amara, A., Ghigo, E., Raoult, D., Capo, C., et al. (2013). Monocyte responses in the context of $\mathrm{Q}$ fever: from a static polarized model to a kinetic model of activation. J. Infect. Dis. 208. doi: 10.1093/infdis/jit266

Meissner, T. B., Li, A., Biswas, A., Lee, K. H., Liu, Y. J., Bayir, E., et al. (2010). NLR family member NLRC5 is a transcriptional regulator of MHC class I genes. Proc. Natl. Acad. Sci. U. S. A. 107, 13794-13799. doi: 10.1073/pnas.1008684107

Meissner, T. B., Li, A., and Kobayashi, K. S. (2012). NLRC5: a newly discovered MHC class I transactivator (CITA). Microbes Infect. 14, 477-484. doi: 10.1016/j. micinf.2011.12.007

Meylan, E., and Tschopp, J. (2006). Toll-like receptors and RNA helicases: two parallel ways to trigger antiviral responses. Mol. Cell 22, 561-569. doi: 10.1016/j.molcel.2006.05.012

Mormone, E., George, J., and Nieto, N. (2011). Molecular pathogenesis of hepatic fibrosis and current therapeutic approaches. Chem. Biol. Interact. 193, 225-231. doi: 10.1016/j.cbi.2011.07.001

Navarro-Gonzalez, J. F., Mora-Fernandez, C., Muros De Fuentes, M., and GarciaPerez, J. (2011). Inflammatory molecules and pathways in the pathogenesis of diabetic nephropathy. Nat. Rev. Nephrol. 7, 327-340. doi: 10.1038/ nrneph.2011.51

Neerincx, A., Lautz, K., Menning, M., Kremmer, E., Zigrino, P., Hosel, M., et al. (2010). A role for the human nucleotide-binding domain, leucine-rich repeatcontaining family member NLRC5 in antiviral responses. J. Biol. Chem. 285, 26223-26232. doi: 10.1074/jbc.M110.109736

Neerincx, A., Rodriguez, G. M., Steimle, V., and Kufer, T. A. (2012). NLRC5 controls basal MHC class I gene expression in an MHC enhanceosome-dependent manner. J. Immunol. 188, 4940-4950. doi: 10.4049/jimmunol.1103136

Null, N. (2003). The International HapMap Project. Nature 426, 789-796. doi: 10.1038/nature02168

Ogura, Y., Bonen, D. K., Inohara, N., Nicolae, D. L., Chen, F. F., Ramos, R., et al. (2001). A frameshift mutation in NOD2 associated with susceptibility to Crohn's disease. Nature 411, 603-606. doi: 10.1038/35079114

Ohno S, K. T., Ohno, Y., Minamoto, T., Suzuki, N., Inoue, M., and Suda, T. (2008). Expression of NLRP7 (PYPAF3, NALP7) protein in endometrial cancer tissues. Anticancer Res. 28, 2493-2497.

Pacifico, R., and Davis, R. L. (2016). Transcriptome sequencing implicates dorsal striatum-specific gene network, immune response and energy metabolism pathways in bipolar disorder. Mol. Psychiatry. 22, 441-449. doi: 10.1038/ mp.2016.94

Pawłowski, K., Pio, F., Chu, Z., Reed, J. C., and Godzik, A. (2001). PAAD - a new protein domain associated with apoptosis, cancer and autoimmune diseases. Trends Biochem. Sci. 26, 85-87. doi: 10.1016/S0968-0004(00)01729-1 
Peng, Y. Y., He, Y. H., Chen, C., Xu, T., Li, L., Ni, M. M., et al. (2016). NLRC5 regulates cell proliferation, migration and invasion in hepatocellular carcinoma by targeting the Wnt/beta-catenin signaling pathway. Cancer Lett. 376, 10-21. doi: 10.1016/j.canlet.2016.03.006

Pihlstrom, B. L., Michalowicz, B. S., and Johnson, N. W. (2005). Periodontal diseases. Lancet 366, 1809-1820. doi: 10.1016/S0140-6736(05)67728-8

Pontigo, J. P., Aguero, M. J., Sanchez, P., Oyarzun, R., Vargas-Lagos, C., et al. (2016). Identification and expressional analysis of NLRC5 inflammasome gene in smolting Atlantic salmon (Salmo salar). Fish Shellfish Immunol. 58, 259-265. doi: 10.1016/j.fsi.2016.09.031

Porter, K. E., and Turner, N. A. (2009). Cardiac fibroblasts: at the heart of myocardial remodeling. Pharmacol. Ther. 123, 255-278. doi: 10.1016/j. pharmthera.2009.05.002

Pradere, J. P., Dapito, D. H., and Schwabe, R. F. (2014). The Yin and Yang of Tolllike receptors in cancer. Oncogene 33, 3485-3495. doi: 10.1038/onc.2013.302

Qiu, L., Ma, T., Chang, G., Liu, X., Guo, X., Xu, L., et al. (2017). Expression patterns of NLRC5 and key genes in the STAT1 pathway following infection with Salmonella pullorum. Gene 597, 23-29. doi: 10.1016/j.gene.2016.10.026

Ranjan, P., Singh, N., Kumar, A., Neerincx, A., Kremmer, E., Cao, W., et al. (2015). NLRC5 interacts with RIG-I to induce a robust antiviral response against influenza virus infection. Eur. J. Immunol. 45, 758-772. doi: 10.1002/ eji.201344412

Ricieri Brito, J. A., Gomes, C. C., Santos Pimenta, F. J., Barbosa, A. A., Prado, M. A., Prado, V. F., et al. (2010). Reduced expression of mir15a in the blood of patients with oral squamous cell carcinoma is associated with tumor staging. Exp. Ther. Med. 1, 217-221. doi: 10.3892/etm_00000035

Rodriguez, G. M., Bobbala, D., Serrano, D., Mayhue, M., Champagne, A., Saucier, C., et al. (2016). NLRC5 elicits antitumor immunity by enhancing processing and presentation of tumor antigens to $\mathrm{CD} 8(+) \mathrm{T}$ lymphocytes. Oncoimmunology 5, e1151593. doi: 10.1080/2162402X.2016.1151593

Rossato, M. F., Hoffmeister, C., Tonello, R., De Oliveira Ferreira, A. P., and Ferreira, J. (2015). Anti-inflammatory effects of vitamin E on adjuvant-induced arthritis in rats. Inflammation 38, 606-615. doi: 10.1007/s10753-014-9967-1

Saran, R., Robinson, B., Abbott, K. C., Agodoa, L. Y., Albertus, P., Ayanian, J., et al. (2017). US Renal Data System 2016 Annual data report: epidemiology of kidney disease in the United States. Am. J. Kidney Dis. 69, A7-A8. doi: 10.1053/j.ajkd.2016.12.004

Spinale, F. G., Coker, M. L., Bond, B. R., and Zellner, J. L. (2000). Myocardial matrix degradation and metalloproteinase activation in the failing heart: a potential therapeutic target. Cardiovasc. Res. 46, 225-238. doi: 10.1016/ S0008-6363(99)00431-9

Staehli, F., Ludigs, K., Heinz, L. X., Seguin-Estevez, Q., Ferrero, I., Braun, M., et al. (2012). NLRC5 deficiency selectively impairs MHC class I- dependent lymphocyte killing by cytotoxic T cells. J. Immunol. 188, 3820-3828. doi: 10.4049/jimmunol.1102671

Staub, E., Dahl, E., and Rosenthal, A. (2001). The DAPIN family: a novel domain links apoptotic and interferon response proteins. Trends Biochem. Sci. 26, 83-85. doi: 10.1016/S0968-0004(00)01717-5

Strutz, F., and Zeisberg, M. (2006). Renal fibroblasts and myofibroblasts in chronic kidney disease. J. Am. Soc. Nephrol. 17, 2992-2998. doi: 10.1681/ ASN.2006050420

Sun, Z. H., Liu, Y. H., Liu, J. D., Xu, D. D., Li, X. F., Meng, X. M., et al. (2017). $\mathrm{MeCP} 2$ regulates PTCH1 expression through DNA methylation in rheumatoid arthritis. Inflammation 40, 1497-1508. doi: 10.1007/s10753-017-0591-8

Takakubo, Y., and Konttinen, Y. T. (2012). Immune-regulatory mechanisms in systemic autoimmune and rheumatic diseases. Clin. Dev. Immunol. 2012, 941346. doi: 10.1155/2012/941346

Theofilopoulos, A. N., Gonzalez-Quintial, R., Lawson, B. R., Koh, Y. T., Stern, M. E., Kono, D. H., et al. (2010). Sensors of the innate immune system: their link to rheumatic diseases. Nat. Rev. Rheumatol. 6, 146-156. doi: 10.1038/ nrrheum.2009.278

Ting, J. P., and Davis, B. K. (2005). CATERPILLER: a novel gene family important in immunity, cell death, and diseases. Annu. Rev. Immunol. 23, 387-414. doi: 10.1146/annurev.immunol.23.021704.115616

Ting, J. P., Lovering, R. C., Alnemri, E. S., Bertin, J., Boss, J. M., Davis, B. K., et al. (2008). The NLR gene family: a standard nomenclature. Immunity 28, 285-287. doi: 10.1016/j.immuni.2008.02.005
Tong, Y., Cui, J., Li, Q., Zou, J., Wang, H. Y., and Wang, R. F. (2012). Enhanced TLR-induced NF-kappaB signaling and type I interferon responses in NLRC5 deficient mice. Cell Res. 22, 822-835. doi: 10.1038/cr.2012.53

Triantafilou, K., Kar, S., van Kuppeveld, F. J., and Triantafilou, M. (2013). Rhinovirus-induced calcium flux triggers NLRP3 and NLRC5 activation in bronchial cells. Am. J. Respir. Cell Mol. Biol. 49, 923-934. doi: 10.1165/ rcmb.2013-0032OC

Tschopp, J., Martinon, F., and Burns, K. (2003). NALPs: a novel protein family involved in inflammation. Nat. Rev. Mol. Cell Biol. 4, 95-104. doi: 10.1038/ nrm1019

Van Golen, R. F., Reiniers, M. J., Olthof, P. B., Van Gulik, T. M., and Heger, M. (2013). Sterile inflammation in hepatic ischemia/reperfusion injury: present concepts and potential therapeutics. J. Gastroenterol. Hepatol. 28, 394-400. doi: 10.1111 /jgh.12072

Villani, A. C., Lemire, M., Fortin, G., Louis, E., Silverberg, M. S., Collette, C., et al. (2009). Common variants in the NLRP3 region contribute to Crohn's disease susceptibility. Nat. Genet. 41, 71-76. doi: 10.1038/ng.285

Wada, J., and Makino, H. (2016). Innate immunity in diabetes and diabetic nephropathy. Nat. Rev. Nephrol. 12, 13-26. doi: 10.1038/nrneph.2015.175

Wang, C., Dai, H., Xiong, Z., Song, Q., Zou, Z., Li, M., et al. (2018a). Loss of DEPTOR in renal tubules protects against cisplatin-induced acute kidney injury. Cell Death Dis. 9, 441. doi: 10.1038/s41419-018-0483-3

Wang, Q., Li, M., Shen, Z., Bu, F., Yu, H., Pan, X., et al. (2018b). The long noncoding RNA MEG3/miR-let-7c-5p axis regulates ethanol-induced hepatic steatosis and apoptosis by targeting NLRC5. Front. Pharmacol. 9, 302. doi: 10.3389/fphar.2018.00302

Wang, S., Zhao, X., Yang, S., Chen, B., and Shi, J. (2018c). Knockdown of NLRC5 inhibits renal fibroblast activation via modulating TGF-beta1/Smad signaling pathway. Eur. J. Pharmacol. 829, 38-43. doi: 10.1016/j.ejphar.2018.03.045

Weber, C. H., and Vincenz, C. (2001). The death domain superfamily: a tale of two interfaces? Trends Biochem. Sci. 26, 475-481. doi: 10.1016/ S0968-0004(01)01905-3

Williams, R. B., Chan, E. K., Cowley, M. J., and Little, P. F. (2007). The influence of genetic variation on gene expression. Genome Res. 17, 1707-1716. doi: 10.1101/ gr.6981507

Wilmanski, J. M., Petnicki-Ocwieja, T., and Kobayashi, K. S. (2008). NLR proteins: integral members of innate immunity and mediators of inflammatory diseases. J. Leukoc. Biol. 83, 13-30. doi: 10.1189/jlb.0607402

Wu, X. M., Hu, Y. W., Xue, N. N., Ren, S. S., Chen, S. N., Nie, P., et al. (2017). Role of zebrafish NLRC5 in antiviral response and transcriptional regulation of MHC related genes. Dev. Comp. Immunol. 68, 58-68. doi: 10.1016/j.dci.2016.11.018

Xu, T., Ni, M. M., Huang, C., Meng, X. M., He, Y. H., Zhang, L., et al. (2015). NLRC 5 mediates IL-6 and IL-1beta secretion in LX- 2 cells and modulated by the NF-kappaB/Smad3 pathway. Inflammation 38, 1794-1804. doi: 10.1007/ s10753-015-0157-6

Xu, T., Ni, M. M., Xing, L., Li, X. F., Meng, X. M., Huang, C., et al. (2016). NLRC5 regulates TGF-betal-induced proliferation and activation of hepatic stellate cells during hepatic fibrosis. Int. J. Biochem. Cell Biol. 70, 92-104. doi: 10.1016/j. biocel.2015.11.010

Yang, Q. Y., Chen, T., Chen, Y. B., and Lan, D. L. (2016). Molecular characterization and expression analysis of the NLR family CARD containing five transcripts in the pig. Pol. J. Vet. Sci. 19, 753-761. doi: 10.1515/pjvs-2016-0095

Yang, K., Shi, J., Hu, Z., and Hu, X. (2019). The deficiency of miR-214-3p exacerbates cardiac fibrosis via miR-214-3p/NLRC5 axis. Clin. Sci. (Lond) 133, 1845-1856. doi: $10.1042 / C S 20190203$

Yao, Y., and Qian, Y. (2013). Expression regulation and function of NLRC5. Protein Cell 4, 168-175. doi: 10.1007/s13238-012-2109-3

Yoneyama, M., and Fujita, T. (2009). RNA recognition and signal transduction by RIG-I-like receptors. Immunol. Rev. 227, 54-65. doi: 10.1111/j.1600-065X.2008.00727.x

Yoshihama, S., Roszik, J., Downs, I., Meissner, T. B., Vijayan, S., Chapuy, B., et al. (2016). NLRC5/MHC class I transactivator is a target for immune evasion in cancer. Proc. Natl. Acad. Sci. U. S. A. 113, 5999-6004. doi: 10.1073/ pnas. 1602069113

Yoshihama, S., Vijayan, S., Sidiq, T., and Kobayashi, K. S. (2017). NLRC5/CITA: a key player in cancer immune surveillance. Trends Cancer 3, 28-38. doi: 10.1016/j.trecan.2016.12.003 
Zaki, M. H., Vogel, P., Malireddi, R. K., Body-Malapel, M., Anand, P. K., Bertin, J., et al. (2011). The NOD-like receptor NLRP12 attenuates colon inflammation and tumorigenesis. Cancer Cell 20, 649-660. doi: 10.1016/j.ccr.2011.10.022

Zeng, Q., Chen, X., Ning, C., Zhu, Q., Yao, Y., Zhao, Y., et al. (2018). Methylation of the genes ROD1, NLRC5, and HKR1 is associated with aging in Hainan centenarians. BMC Med. Genomics 11, 7. doi: 10.1186/s12920-018-0334-1

Zhang, W., Zhu, J., Du, Z., Yu, J., Xu, Y., and Wang, F. (2015). Intraarticular gene transfer of SPRY2 suppresses adjuvant-induced arthritis in rats. Appl. Microbiol. Biotechnol. 99, 6727-6735. doi: 10.1007/s00253-015-6618-x

Zhang, T., Li, H., Shi, J., Li, S., Li, M., Zhang, L., et al. (2016a). p53 predominantly regulates IL- 6 production and suppresses synovial inflammation in fibroblastlike synoviocytes and adjuvant-induced arthritis. Arthritis Res. Ther. 18, 271. doi: 10.1186/s13075-016-1161-4

Zhang, X., Justice, A. C., Hu, Y., Wang, Z., Zhao, H., Wang, G., et al. (2016b). Epigenome-wide differential DNA methylation between HIVinfected and uninfected individuals. Epigenetics 11, 750-760. doi: 10.1080/15592294.2016.1221569

Zhang, M., Kong, B., Huang, M., Wan, R., Armstrong, L. E., Schumacher, J. D., et al. (2018). FXR deletion in hepatocytes does not affect the severity of alcoholic liver disease in mice. Dig. Liver Dis. 50, 1068-1075. doi: 10.1016/j. dld.2018.04.009

Zhang, Y. Z., Yao, J. N., Zhang, L. F., Wang, C. F., Zhang, X. X., and Gao, B. (2019). Effect of NLRC5 on activation and reversion of hepatic stellate cells by regulating the nuclear factor- $\kappa \mathrm{B}$ signaling pathway. World J. Gastroenterol. 25, 3044-3055. doi: 10.3748/wjg.v25.i24.3044

Zhong, C., Pu, L., Fang, M., Rao, J., and Wang, X. (2018). ATRA regulates innate immunity in liver ischemia/reperfusion injury via RARa/Akt/Foxol signaling. Biol. Pharm. Bull. 41, 530-535. doi: 10.1248/bpb.b17-00832

Zhou, H., Yu, X., and Zhou, G. (2017). NLRC5 silencing ameliorates cardiac fibrosis by inhibiting the TGF- $\beta 1 / \mathrm{Smad} 3$ signaling pathway. Mol. Med. Rep. 16, 3551-3556. doi: 10.3892/mmr.2017.6990

Zupin, L., Navarra, C. O., Robino, A., Bevilacqua, L., Di Lenarda, R., Gasparini, P., et al. (2017). NLRC5 polymorphism is associated with susceptibility to chronic periodontitis. Immunobiology 222, 704-708. doi: 10.1016/j. imbio.2017.01.001

Conflict of Interest: The authors declare that the research was conducted in the absence of any commercial or financial relationships that could be construed as a potential conflict of interest.

Copyright (c) 2019 Wang, Liu, Xia, Chen, Liang, Xia and Li. This is an open-access article distributed under the terms of the Creative Commons Attribution License (CC $B Y)$. The use, distribution or reproduction in other forums is permitted, provided the original author(s) and the copyright owner(s) are credited and that the original publication in this journal is cited, in accordance with accepted academic practice. No use, distribution or reproduction is permitted which does not comply with these terms. 